\title{
The Incidence of Atypical Femoral Fractures in Patients with Rheumatic Disease: Yamagata Prefectural Committee of Atypical Femoral Fractures (YamaCAFe) Study
}

\author{
Yuya Takakubo, ${ }^{1}$ Daichi Ohta, ${ }^{1}$ Masaji Ishi, ${ }^{2}$ Juji Ito, ${ }^{1}$ Hiroharu Oki, ${ }^{1}$ \\ Yasushi Naganuma, ${ }^{1}$ Tomohiro Uno, ${ }^{1}$ Akiko Sasaki, ${ }^{1}$ Takeru Akabane, ${ }^{3}$ \\ Katsuyuki Dairaku, ${ }^{4}$ Shinichi Goto, ${ }^{5}$ Yasuo Goto, ${ }^{6}$ Yumiko Kanauchi, ${ }^{7}$ \\ Shinji Kobayashi, ${ }^{8}$ Taku Nakajima, ${ }^{9}$ Keiji Masuda, ${ }^{10}$ Michiharu Matsuda, ${ }^{11}$ \\ Nariyuki Mura, ${ }^{12}$ Kenji Takenouchi, ${ }^{13}$ Hiroyuki Tsuchida, ${ }^{14}$ Yasushi Onuma, ${ }^{15}$ \\ Junichirou Shibuya, ${ }^{16}$ Mitsuyoshi Seino, ${ }^{17}$ Osamu Yamaguchi, ${ }^{18}$ \\ Ken Hiragami, ${ }^{14}$ Yasuhiro Urayama, ${ }^{19}$ Takashi Furukawa, ${ }^{12}$ Shouta Okuda, ${ }^{20}$ \\ Ken Ogura, ${ }^{21}$ Takeshi Nakamura, ${ }^{22}$ Kan Sasaki, ${ }^{1}$ Tsuneo Konta ${ }^{23}$ and \\ Michiaki Takagi ${ }^{1}$
}

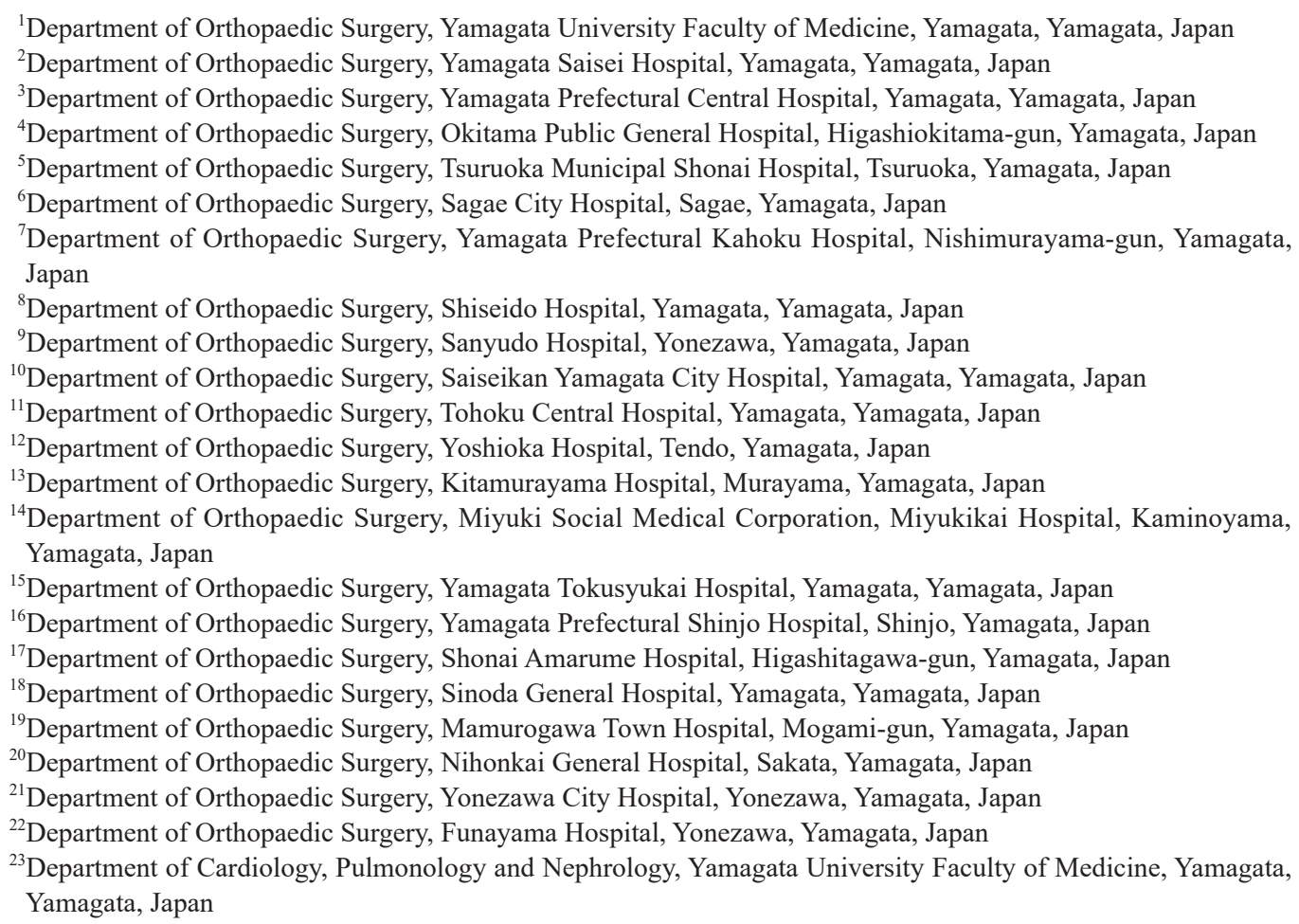

Atypical femoral fractures (AFFs) have been reported to occur with minimal or spontaneous subtrochanteric and femoral shaft fractures with a characteristic transverse pattern, compared with typical femoral fractures in young patients with high-energy trauma. AFFs are related to long-term use of bisphosphonates (BPs), glucocorticoids and rheumatic diseases. We have estimated a blind analysis of AFFs in rheumatic patients receiving BPs and glucocorticoids ordinary over a long time in all Yamagata prefectural area through radiographic examination. The 123 AFFs including suspected cases over six years were collected and reviewed by two independent orthopedic surgeons. We found 86 patients with a total of 99 AFFs between 2009 and 2014 (1.43 cases/100,000 person/year). Of these 99 AFFs, 11 were in 8 rheumatic patients including three patients with bilateral AFFs. The incidence of AFFs in rheumatic patients had trend to

Received May 8, 2017; revised and accepted August 17, 2017. Published online September 5, 2017; doi: 10.1620/tjem.242.327.

Correspondence: Yuya Takakubo, M.D., Ph.D., Department of Orthopaedic Surgery, Yamagata University Faculty of Medicine, 2-2-2 Iida Nishi, Yamagata, Yamagata 990-9585, Japan.

e-mail: takakubo-y@med.id.yamagata-u.ac.jp 
increase from 2012. The mean age of all 8 patients was 54.9 years. All 8 patients received BPs and $7 / 8$ received prednisolone (PSL). The mean dose of PSL was $14 \mathrm{mg} /$ day. Compared to patients with unilateral AFFs, those with bilateral AFFs in rheumatic patients were on a higher dose of PSL $(20 \mathrm{mg} / \mathrm{day}$ vs. $7 \mathrm{mg} /$ day) and had less femoral neck-shaft angle $\left(129^{\circ}\right.$ vs. $\left.136^{\circ}, p<0.05\right)$. In conclusion, the incidence of AFFs in rheumatic patients showed a trend to increase from 2012 to 2014 in Yamagata prefecture. Careful management of AFFs is of particular importance in rheumatic patients who have taken high doses of PSL and have small femoral neck-shaft angle.

Keywords: atypical femoral fracture; femur; prednisolone; rheumatic disease; small femoral neck-shaft angle Tohoku J. Exp. Med., 2017 August, 242 (4), 327-334. C 2017 Tohoku University Medical Press

\section{Introduction}

Atypical femoral fractures (AFFs) have been reported to occur with no trauma or minimal substantial force applied to the affected subtrochanteric and femoral shaft fractures with a characteristic transverse or short oblique pattern, compared with typical femoral fractures in young patients with high-energy trauma such as traffic or fallingdown accidents. AFFs have been reported to be related to long-term use of bisphosphonates (BPs) and glucocorticoids, rheumatic diseases, renal disease, and diabetes mellitus (Black et al. 2010; Shane et al. 2010; Schilcher et al. 2011, 2014). A number of recent case reports and series of AFF have identified a subgroup of all the femoral subtrochanteric and shaft fractures.

Osteoporosis is a major cause of disability that affects over 75 million individuals in Japan, the United States, and Europe, and has both, health and economic disadvantages. Nearly one in every four men and one in every two women with osteoporosis will have fractures during their lifetime (Nieves and Cosman 2010). If patients with rheumatic disease take prednisolone (PSL) for many years, they have a higher risk of developing osteoporosis, even at a young age.

BPs are currently one of the most widely used drugs for the treatment of osteoporosis (Schilcher et al. 2014). They work by decreasing bone resorption and increasing bone mineral density, thereby decreasing the occurrence of both, vertebral and non-vertebral fractures in patients with rheumatic disease (Das De et al. 2010). However, many studies have recently reported that BP use has a strong, duration-dependent association with AFFs (Odvina et al. 2005; Dell et al. 2012; Meier et al. 2012; Schilcher et al. 2014) and that prolonged use of BPs may increase the risk of atypical fractures by impairing the healing of naturally occurring micro cracks in the bone (Ettinger et al. 2013; Schilcher et al. 2014). Alternatively, femoral geometry has also been associated with the incidence of AFFs. As femoral neck-shaft angle in healthy Japanese women has been found to be smaller than that in American women (Nakamura et al. 1994), it has been reported that Asian women are more likely to sustain AFFs than Caucasian women (Oh et al. 2014; Shane et al. 2014; Lo et al. 2016). In addition, small femoral neck-shaft angle was reported to be associated with development of AFFs in long-term BPs users (Taormina et al. 2014).
The elderly population in Japan has been increasing each year; people $>65$ years of age comprised $25.9 \%$ of the entire population in 2014, and this percentage is expected to increase to $30.4 \%$ by 2025 (National Institute of Population and Social Security Research 2014). The Yamagata prefectural area has 1,140,000 people, 30.0\% of whom were $>65$ years of age in 2014 (Yamagata prefecture, Health and longevity Promotion Section 2014). In fact, life span of the patients with rheumatoid arthritis has closed to that of general population year by year because the mortality in patients with rheumatoid arthritis has decreased over the past decades due to earlier diagnosis and more aggressive therapies (Gonzalez et al. 2007; Dadoun et al. 2013). The incidence of AFFs in rheumatic patients is therefore expected to increase with the expanding elderly population, many of whom are receiving therapy to treat osteoporosis. In this study, we retrospectively examined clinical factors and femur geometry in all rheumatic patients who had an AFF between 2009 and 2014 in the Yamagata prefectural area, one of the area with the largest aging population in North Japan.

\section{Materials and Methods}

Study design

As part of the Yamagata Prefectural Committee of Atypical Femoral Fractures Study (YamaCAFe study), we retrospectively examined patients in all twenty-seven hospitals in the Yamagata prefecture in North Japan that have emergency, admission, and surgery records of the orthopedic departments between 2009 and 2014. Twenty-four of these hospitals had performed orthopedic surgeries. The total number of femoral fractures in our prefecture was 12,343 over six years which searched them by chief or senior orthopedic surgeons of each hospital. Nineteen of these hospitals had treated at least more than one AFF throughout the length of study (Fig. 1). The 123 AFF including suspected cases was selected from nineteen hospitals and then the radiographs of all of patients who had hip and femoral shaft fractures were simultaneously reviewed using radiographic analyses by two independent orthopedic surgeons (Y.T and D.O) according to the second report by the American Society for Bone and Mineral Research (ASBMR) Task Force 2013 (Shane et al. 2014). We excluded 24 cases which consist of 18 femur trochanteric fractures, 3 supracondylar fractures of femur and 3 AFFs who were injured excluding the study period. The study protocol was approved by the ethics committee of Yamagata University (No. 2014-259). 


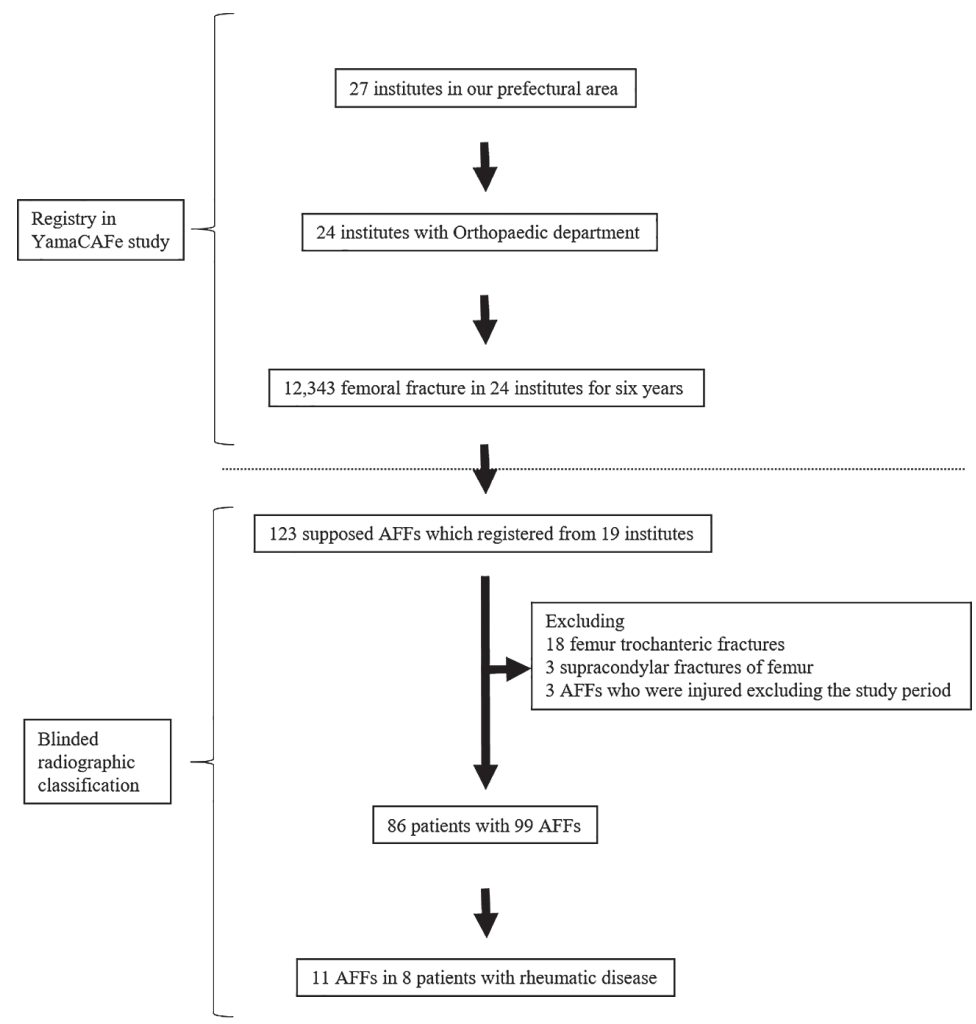

Fig. 1. A CONSORT diagram of the study design.

A CONSORT diagram showing the study design, comprising patients with common femoral fractures and atypical femoral fractures who were registered in the study population. YamaCAFe study, Yamagata Prefectural Committee of Atypical Femoral Fractures Study; AFF, atypical femoral fracture.

Table 1. Clinical characteristics of patients with rheumatic disease (RD) and atypical femoral fracture (AFF).

\begin{tabular}{|c|c|c|c|c|c|c|c|c|c|c|c|c|}
\hline No & Case & $\mathrm{RD}$ & $\begin{array}{c}\text { Age/Sex } \\
(\mathrm{yrs} /)\end{array}$ & Area & $\begin{array}{c}\text { Duration of post-operative } \\
\text { observation } \\
\text { (months) }\end{array}$ & $\begin{array}{l}\text { PSL dose } \\
\text { at injury } \\
\text { (mg/day) }\end{array}$ & $\begin{array}{l}\text { PSL duration } \\
\text { (months) }\end{array}$ & $\begin{array}{c}\text { Maximum } \\
\text { dosage } \\
\text { of PSL } \\
\text { (mg/day) }\end{array}$ & $\mathrm{BP}$ & $\begin{array}{c}\text { BP } \\
\text { treatment } \\
\text { duration } \\
\text { (months) }\end{array}$ & $\begin{array}{l}\text { BP using } \\
\text { after AFF }\end{array}$ & $\begin{array}{l}\text { Protonpump } \\
\text { inhibitor }\end{array}$ \\
\hline 1 & a rt & SLE & $33 / \mathrm{F}$ & shaft & 70 & 15 & 120 & - & Risedronate & 36 & + & - \\
\hline 2 & a lt & SLE & $36 / \mathrm{F}$ & shaft & 48 & 12.5 & 168 & - & Risedronate & 36 & + & - \\
\hline 3 & b lt & SLE & $37 / \mathrm{F}$ & subtrochanteric & 24 & 15 & 36 & 30 & Alendronate & 24 & + & - \\
\hline 4 & $\mathrm{~b} \mathrm{rt}$ & SLE & $39 / \mathrm{F}$ & subtrochanteric & 14 & 15 & 36 & 30 & Alendronate & 36 & - & - \\
\hline 5 & $\mathrm{clt}$ & PM & $72 / \mathrm{F}$ & subtrochanteric & 20 & 30 & 60 & 30 & Alendronate & 48 & - & + \\
\hline 6 & $\mathrm{c} \mathrm{rt}$ & PM & $72 / \mathrm{F}$ & shaft & 14 & 30 & 65 & 30 & Alendronate & 48 & - & + \\
\hline 7 & d & PN & $62 / \mathrm{F}$ & subtrochanteric & 23 & 15 & 84 & 40 & Alendronate & 84 & - & + \\
\hline 8 & $\mathrm{e}$ & RA & $51 / \mathrm{F}$ & subtrochanteric & 12 & 10 & 120 & 10 & Alendronate & 120 & - & + \\
\hline 9 & $\mathrm{f}$ & $\mathrm{SSC}$ & $73 / \mathrm{F}$ & subtrochanteric & 24 & 5 & 216 & - & Alendronate & 84 & + & + \\
\hline 10 & $\mathrm{~g}$ & SLE & $49 / \mathrm{F}$ & subtrochanteric & 13 & 5 & 108 & 20 & Alendronate & 36 & - & + \\
\hline 11 & $\mathrm{~h}$ & RA & $80 / \mathrm{F}$ & shaft & 35 & 0 & 0 & 0 & Minodronate & 24 & - & - \\
\hline Average & & & 54.9 & & 27 & 13.9 & 101 & 27.1 & & 52 & $4 / 11$ & $6 / 11$ \\
\hline
\end{tabular}

SLE, systemic lupus erythematosus; PM, polymyelitis; RA, rheumatoid arthritis; SSC, systemic sclerosis; PN, polyarteritis nodosa; PSL, prednisolone; BP, bisphosphonate.

\section{Study procedure}

For each atypical femoral fracture, data were obtained from registries and medical records of each hospital on the following factors: part and type of fracture; patient drug use; and patient comorbidities, including rheumatic diseases; previous medical history; treatment used for AFFs (including surgery); complications after the fractures; and time until fracture union. Two independent orthopedic surgeons (Y.T and D.O) also estimated femoral neck-shaft angle and lateral bowing angle of femur on femoral anteroposterior radiographic images (Hagen et al. 2014; Oh et al. 2014) (Tables 1 and 2). We used accurate anteroposterior radiographic images of the affected femurs before the injury for estimation their angle. If we can not use them, we selected pre- or post-operative images of opposite femur [7 AFFs in 5 cases $(7 / 11 ; 64 \%)]$. To quantify the femoral neck-shaft angle, it 
Table 2. Clinical and radiographic characteristics of patients with rheumatic disease and atypical femoral fracture.

\begin{tabular}{cccccccc}
\hline No & $\begin{array}{c}\text { Prodromal } \\
\text { symptoms }\end{array}$ & $\begin{array}{c}\text { Periosteal } \\
\text { reaction }\end{array}$ & $\begin{array}{c}\text { Femoral neck- } \\
\text { shaft angle } \\
\text { (degrees) }\end{array}$ & $\begin{array}{c}\text { Lateral bowing } \\
\text { angle or femur } \\
\text { (degrees) }\end{array}$ & $\begin{array}{c}\text { Time to union } \\
\text { of fracture } \\
\text { (months })\end{array}$ & Teriparatide & Ultrasound \\
\hline 1 & + & + & 130 & 7 & 12 & - & - \\
2 & + & + & 130 & 6 & 10 & - & - \\
3 & - & + & 134 & 4 & 13 & - & + \\
4 & - & + & 135 & 4 & 12 & - & + \\
5 & + & + & 120 & 9 & 16 & + & + \\
6 & + & + & 125 & 5 & 6 & + & + \\
7 & - & - & 130 & 3 & 12 & + & + \\
8 & - & + & 140 & 10 & - & + & + \\
9 & + & + & 135 & 8 & 12 & + & + \\
10 & + & + & 141 & 6.5 & 9 & - & - \\
11 & - & + & 138 & 8 & 24 & - & + \\
\hline Average & $6 / 11$ & $10 / 11$ & 132.5 & 6.4 & 13 & $5 / 11$ & $8 / 11$ \\
\hline
\end{tabular}

was defined as the angle formed by the intersection of a line through the center of the femoral shaft and a line down the center of the femoral neck (Hagen et al. 2014). To quantify the lateral bowing angle of femur, the diaphysis of the femur was divided into four equal parts, and a line was drawn in each quarter to describe the midpoint of the endosteal canal. The degree of lateral bowing was defined as the angulation between the proximal and distal quarters of the femoral diaphysis (Oh et al. 2014). Measurements of each angle were recorded as independent data.

The information about the population of the Yamagata prefecture was obtained from data from the prefectural government (Yamagata prefecture, Health and longevity Promotion Section 2014). While the overall populations decreased from $1,180,000$ people in 2009 to $1,140,000$ in 2014 , the overall population of elderly people increased from $27.3 \%$ in 2009 to $30.0 \%$ in 2014 in our prefectural area.

\section{Statistical analysis}

One-factor ANOVA for analysis of variance and MannWhitney's U test for nonparametric test of the null hypothesis were performed using the PASW 18 software (SPSS Institute Inc., Chicago, IL, USA). Values of $p<0.05$ were considered statistically significant.

\section{Results}

We collected data on 86 patients with a total of 99 AFFs within our prefectural area between 2009 and 2014 (1.43 cases $/ 100,000$ person/year). Annual number of total AFF was 8 in 2009, 19 in 2010, 12 in 2011, 15 in 2012, 26 in 2013, and 19 in 2014 (Ohta et al. 2016). Of these 99 AFFs, eleven were in eight patients with rheumatic disease, all of whom were women and three patients had bilateral AFFs (Fig. 2). The number of AFFs in rheumatic patients had trend to increase from 2012 (Fig. 3). The mean age of affected women was 54.9 years (range: 33-80 years). Regarding comorbid conditions, five AFFs in three patients had systematic lupus erythematosus; two in one patient had polymyositis; other two in two patients had rheumatoid arthritis; one had polyarteritis nodosa; and other one had systemic sclerosis. Regarding fracture types, seven were subtrochanteric and four were diaphyseal femoral fractures. All eight patients (100\%) received BPs for a mean duration of 52 months (range: $24-120$ months) and 7/8 (88\%) also received PSL for a mean duration of 101 months (range: 36-216 months). The mean dosage of PSL was $13.9 \mathrm{mg} /$ day (range: $0-30 \mathrm{mg} /$ day) at affecting AFF and the mean maxim dosage of PSL was $27.1 \mathrm{mg} /$ day $(0-40)$ excluding three AFFs in two cases which could not been collected their data (Table 1). In six of eleven cases, the patients with AFFs had prodromal pain (55\%). The mean femoral neckshaft angle was $132.5^{\circ}\left(120^{\circ}-141^{\circ}\right)$ and lateral bowing angle of femur was $6.4^{\circ}\left(3^{\circ}-10^{\circ}\right)$ (Table 2$)$.

In comparison with patients who had unilateral AFFs, those who had bilateral AFFs received a higher dose of PSL $(20 \mathrm{mg} /$ day vs. $7 \mathrm{mg} /$ day, $\mathrm{p}<0.05)$ and had less femoral neck-shaft angle $\left(129^{\circ}\right.$ vs. $\left.136^{\circ}, \mathrm{p}<0.05\right)$; however, they received PSL for a shorter duration (62.5 months vs. 132 months, $\mathrm{p}<0.05$ ) (Table 3).

After sustaining the fractures, the use of BPs was stopped in seven patients (Table 1). Surgery using intramedullary nail fixation was performed in all but one patient for whom a locking plate was used. After operative wounds were healed, teriparatide with low-intensity pulsed ultrasonography was administered in five cases, and low-intensity pulsed ultrasonography without teriparatide administration was performed in three cases. The mean duration of postoperative observation was 28 months (range: 12-70 months). At last follow-up, an evaluation by radiography or computed tomography revealed that $10 / 11$ femurs were healed at the fracture site after the mean duration of 12.6 months (range: 6-24 months). Of 10 AFFs which showed the healing of fracture site (Table 2), the mean duration of healing was 13.3 months (9-24 months) in 4 AFFs treated with both teriparatide and low-intensity pulsed ultrasonography, 16.3 months (12-24 months) in 3 AFFs treated with 


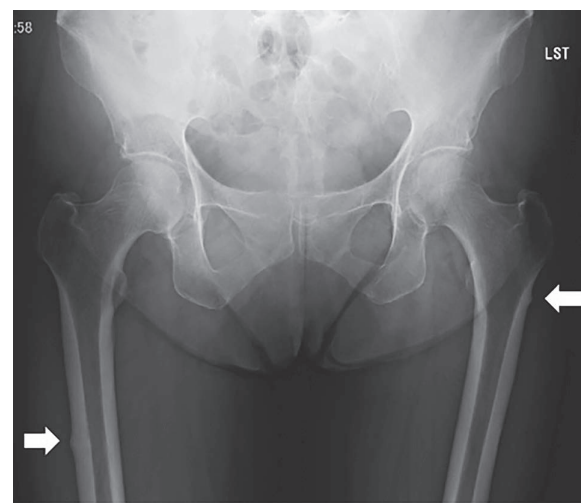

b

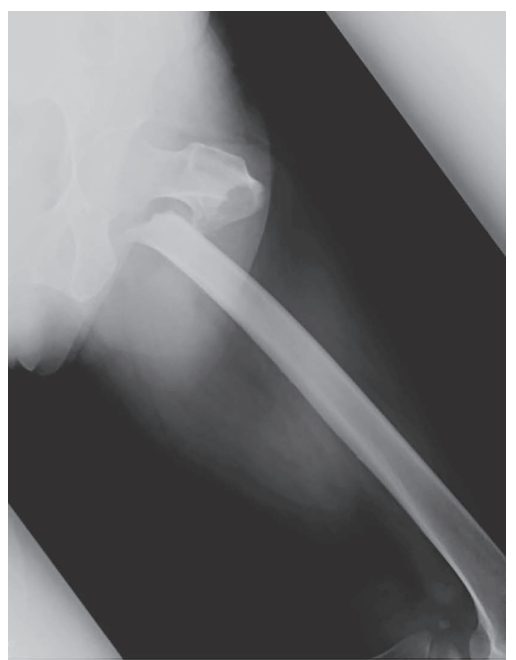

Fig. 2. Radiographic image of femurs before and after the left fracture.

A 72-year-old woman who had been taking $15 \mathrm{mg}$ per day of PSL for five years for dermatomyositis had felt prodromal pain with periosteal reactions seen radiographically at the lateral cortex of her central femoral area one month before her fracture (a). She sustained a left atypical femoral fracture without any trauma to the bone (b, case of No. 5 and 6 in Tables 1 and 2).

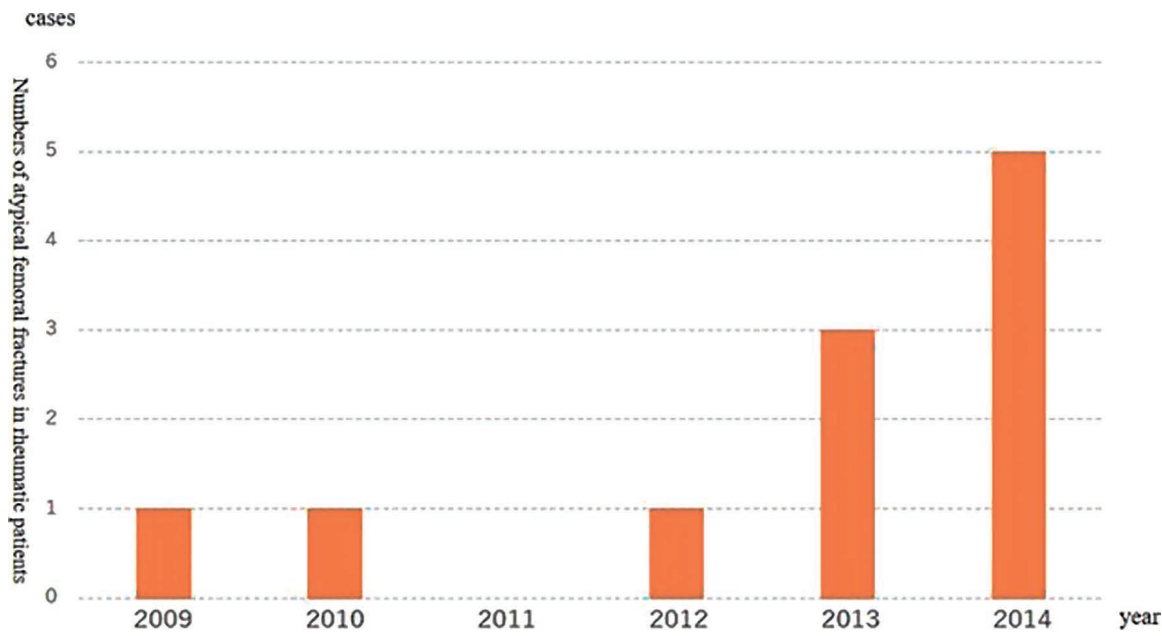

Fig. 3. The trend of atypical femoral fractures in the patient with rheumatic disease.

Atypical femoral fractures in the patients with rheumatic disease have a trend of increasing year by year from 2012 to 2014.

only low-intensity pulsed ultrasonography, and 10.3 months (9-12 months) $(\mathrm{p}=0.09)$ in 3 AFFs untreated with teriparatide or low-intensity pulsed ultrasonography.

\section{Discussion}

Although there were more than $12 \mathrm{AFFs}$ per year since 2010 in our prefectural area, there was no trend for the annual incidence of AFFs to increase over the study period. However, between 2009 and 2014, we identified eleven AFFs in eight women with rheumatic diseases, with the number of AFFs in this disease group increasing annually since 2012. All eight patients received BPs and seven also received PSL. Patients with bilateral AFFs received a higher dose of PSL and had less femoral neck-shaft angle than those with unilateral AFFs $(\mathrm{p}<0.05)$.
BPs have been reported to reduce the risk of osteoporotic fractures in elderly peoples (Black et al. 2010; Das De et al. 2010). Although osteoporotic hip fractures have recently been decreasing worldwide, this has not been the case in Japan (Cooper et al. 2011; Bawa et al. 2015). In Japan, etidronate as a first-generation bisphosphonate has been approved for treatment of osteoporosis since 1996, alendronate as a second-generation since 2001, risedronate and minodronate as a third-generation since 2001 and 2009, respectively, and then, BP therapy was spread gradually (Kishimoto and Maehara 2015). In comparison to that in the Western countries, BP was authorized for treating osteoporosis with time-lag previously (Hagen et al. 2014; Kishimoto and Maehara 2015). Moreover, the incidence of AFFs was significantly correlated to the use of BPs and the 
Table 3. Characteristics of bilateral atypical femoral fracture (AFF) and unilateral AFF groups.

\begin{tabular}{|c|c|c|c|}
\hline \multirow{2}{*}{ Case } & & \multirow{2}{*}{$\frac{\text { Bilateral AFF group }}{3 \text { ( } 6 \text { femurs })}$} & \multirow{2}{*}{$\frac{\text { Unilateral AFF group }}{5}$} \\
\hline & & & \\
\hline $\mathrm{RD}$ & & SLE 2, PM 1 & RA 2, SLE $1, \operatorname{SSC} 1$, PN 1 \\
\hline \multirow[t]{2}{*}{ Mean age } & (years) & 48.2 & 63 \\
\hline & & $(33-72)$ & $(51-80)$ \\
\hline $\mathrm{M} / \mathrm{F}$ & & $0 / 6$ & $0 / 5$ \\
\hline \multirow[t]{2}{*}{ PSL dose } & & $20^{*}$ & 7 \\
\hline & (mg/day) & $(15-30)$ & $(0-15)$ \\
\hline \multirow[t]{2}{*}{ PSL duration } & & 62.5 & $132 *$ \\
\hline & (months) & $(36-65)$ & $(0-216)$ \\
\hline \multirow[t]{2}{*}{$\mathrm{BP}$ treatment duration } & & 38 & 69.6 \\
\hline & & $(24-48)$ & $(24-120)$ \\
\hline Prodromal symptoms & (months) & $4 / 6$ & $2 / 5$ \\
\hline \multicolumn{2}{|c|}{ Periosteal reaction of the lateral cortex } & $6 / 6$ & $4 / 5$ \\
\hline \multicolumn{2}{|c|}{ Femoral neck-shaft angle } & $129^{*}$ & 136 \\
\hline & (degrees) & $(120-135)$ & $(130-141)$ \\
\hline \multicolumn{2}{|c|}{ Lateral bowing angle of femur } & 5.5 & 6.8 \\
\hline & (degrees) & $(4-9)$ & $(3-10)$ \\
\hline \multirow{3}{*}{\multicolumn{2}{|c|}{$\begin{array}{l}\text { Fracture site of femur } \\
\qquad \text { (subtrochanteric / shaft) } \\
\text { (cases) } \\
\text { Time to union of fracture }\end{array}$}} & $3 / 3$ & $4 / 1$ \\
\hline & & & \\
\hline & & 11.5 & 14.3 \\
\hline & (months) & $(6-13)$ & $(9-24)$ \\
\hline Non-union of fractures & & $0 / 6$ & $1 / 5$ \\
\hline Teriparatide & & $2 / 6$ & $3 / 5$ \\
\hline Ultrasound & & $4 / 6$ & $4 / 5$ \\
\hline
\end{tabular}

$\mathrm{RD}$, rheumatic disease; SLE, systemic lupus erythematosus; PM, polymyositis; RA, rheumatoid arthritis; SSC, systemic sclerosis; PN, polyarteritis nodosa; PSL, prednisolone; BP, bisphosphonate.

*Mann-Whitney's U test $(\mathrm{p}<0.05)$.

duration of receiving BP (Dell et al. 2012; Schilcher et al. 2014). In fact, all the patients with rheumatic disease who were injured with AFFs had received BPs for at least two years in our study. For this reason, the incidence of AFFs in the patients with rheumatic disease may have increased more recently in our prefectural area, with long-term administration of BPs in the increasing aging population. In this context, several studies showed the possibility of a link between BP use and the occurrence of low-energy or spontaneous subtrochanteric and femoral shaft fractures with a characteristic pattern in an area of cortical hypertrophy (Shane et al. 2010, 2014; Schilcher et al. 2011), although the incidence of rheumatic disease have reported not to change at least for our study periods (Firestein et al. 2017).

On the other hand, the mail survey in every year conducted from 2010 by the Japan Orthopedic Association in approximately 3,100 institutes in Japan found no change in the total number of AFFs: they reported 398 cases in 2010, 355 in 2011, 371 in 2012, 374 in 2013, and 406 in 2014, but the AFF in the patients with rheumatoid arthritis was increasing annually in their survey: 9 cases in $2010(2.3 \%)$, 10 in 2011 (2.8\%), 19 in 2012 (5.0\%), 23 in 2013 (6.1\%), and 26 in 2014 (6.4\%) (Osteoporotic Committee of Japanese Orthopaedics Association 2015, 2016). However, other rheumatic diseases were not described and radiographic data in these surveys were not registered and only included diagnoses from select orthopedic surgeons in each institute. On the other hand, it was reported that the rate of BP use in AFF patients increased from $29.9 \%$ in 2010 to 63.8\% in 2014 (Osteoporotic Committee of Japanese Orthopaedics Association 2015, 2016).

In addition, the 2010 definition of AFFs by ASBMR from 2010 till 2012 and the 2013 definition from 2013 was used for the mail surveys in Japan (Osteoporotic Committee of Japanese Orthopaedics Association 2015), but their accuracy in diagnosing AFFs is currently unknown. In one meta-analysis, Gedmintas et al. (2013) showed the importance of radiographic confirmation in defining AFFs. They reported the pooled adjusted relative risk of AFFs was 
28.16 (95\% CI, 13.30-59.59) in their study in which radiography was used to confirm the occurrence of an AFF, compared to 1.70 (95\% CI, 1.22-2.37), in which radiographic examination was not used.

In our study, blind review by two independent orthopedic surgeons resulted in the exclusion of 21 cases that had been registered as AFFs in each hospital according to the criteria of ASBMR 2013 and the remaining 3 cases due to out of this study period. These facts supported the importance of radiographic examination for registrations of AFF (Gedmintas et al. 2013). In addition, the use of BPs was not stopped after the first fracture in two of the three cases with bilateral AFFs in this study, as their doctors may not have recognized the risk of sustaining an AFF in the contralateral femur with continued use of BPs. Because the clinical definition and pathological condition of AFFs was less commonly known at least before 2010 (Shane et al. 2010, 2014), it was expected the diagnosis of AFFs was not standardized in orthopedic surgeons of general hospitals, at least in our prefectural area.

For treatment of complete fractures in AFF patients, surgical therapy and discontinuation of BP therapy is necessary (Shane et al. 2014; Koh et al. 2017). Teriparatide has been shown to possibly accelerate the healing of AFFs (Shane et al. 2014; Schilcher 2015; Miyakoshi et al. 2015); however, Watts et al. (2017) did not find a consistent effect of teriparatide on healing of AFFs. In our study, teriparatide with low-intensity pulsed ultrasound was used for treatment in five cases (46\%). However, the effect of teriparatide and/or low-intensity pulsed ultrasonography was not revealed in this study.

Due to the higher likelihood of femoral bowing in Asian women, they are at a higher risk of AFFs (Oh et al. 2014; Shane et al. 2014; Lo et al. 2016; Hyodo et al. 2017). A previous study showed that bilateral femoral fractures were present in $40 \%$ of AFFs patients in comparison to $2 \%$ of ordinary fractures, and that an additional $21 \%$ of AFFs had focal cortical hypertrophy of the contralateral femur (Oh et al. 2014; Shane et al. 2014). In addition, varus angles of the femoral neck-shaft under 128.3 degrees as cut-off point were reported to be associated with development of AFFs in long-term bisphosphonate users (Taormina et al. 2014). In our study, bilateral AFF patients had less femoral neck-shaft angle and were on a higher dose of PSL than patients with unilateral AFF, although the duration of their PSL use was shorter. In patients with small femoral neck-shaft angle and/or rheumatic disease, those who use high doses of PSL and BPs especially for a long time may be at a higher risk of sustaining bilateral AFFs (Somford et al. 2009; Taormina et al. 2014; Koh et al. 2016; Sato et al. 2016). Therefore, physicians should carefully check for signs of prodromal symptoms and review radiographic images for incomplete fractures in the contralateral femur in rheumatic patients who have sustained AFF (Koh et al. 2016).

In addition, glucocorticoid including PSL was reported to be one of risk factor for suffering AFFs and also steroid induced-osteoporosis (Shane et al. 2010, 2014). Because the patients with rheumatic disease mostly have to receive it and bisphosphonate for a long time due to prevention of steroid-induced osteoporosis, they also have several risks of sustaining AFFs (Sato et al. 2016; Koh et al. 2016).

One of the limitations of this study is that our sample size of AFF cases in rheumatic patients is relatively quite small, although all hospitals which have the clinical records of emergency, admission and orthopedic surgery in our prefectural area were enrolled in this study. Risk factor could not be estimated by multivariable logistic regression analysis due to small population. If the population of the study was larger, we believe risk factors may be revealed for suffering AFFs in the patients with rheumatic diseases. This would be improved by a nation-wide survey of AFFs reviewed by radiographic examinations. Second limitation was the numbers of the patient with rheumatic disease which received BP therapy were not revealed in our prefectural area in this study. In next study, we should investigate the incidence of AFFs in the patients with rheumatic disease who received BP in our prefectural area. The third limitation is that this study is retrospective; however, we started a prospective study from 2016.

Eleven AFFs in eight rheumatic patients were observed between 2009 and 2014 in the Yamagata prefectural area in the super-aging area of north Japan, with the increasing number of AFFs since 2012. We found that careful management and treatment of AFFs in rheumatic patients is required even after surgery, as all of our cases showed delayed union or non-union of the fracture site. Furthermore, if patients have small femoral neck-shaft angle and/or are on a high dose of PSL with BPs, there is risk of AFFs in the bilateral femurs.

\section{Acknowledgments}

We thank a lot for all members of YamaCAFe study and Ms. Itsuho Tomuro for her great supports.

\section{Conflict of Interest}

The authors declare no conflict of interest.

\section{References}

Bawa, H.S., Weick, J. \& Dirschl, D.R. (2015) Anti-osteoporotic therapy after fragility fracture lowers rate of subsequent fracture: analysis of a large population sample. J. Bone Joint Surg. Am., 97, 1555-1562.

Black, D.M., Kelly, M.P., Genant, H.K., Palermo, L., Eastell, R., Bucci-Rechtweg, C., Cauley, J., Leung, P.C., Boonen, S., Santora, A., de Papp, A. \& Bauer D.C.; Fracture Intervention Trial Steering Committee, and HORIZON Pivotal Fracture Trial Steering Committee (2010) Bisphosphonates and fractures of the subtrochanteric or diaphyseal femur. N. Engl. J. Med., 362, 1761-1771.

Cooper, C., Cole, Z.A., Holroyd, C.R., Earl, S.C., Harvey, N.C., Dennison, E.M., Melton, L.J., Cummings, S.R. \& Kanis, J.A.; IOF CSA Working Group on Fracture Epidemiology (2011) Secular trends in the incidence of hip and other osteoporotic fractures. Osteoporos. Int., 22, 1277-1288. 
Dadoun, S., Zeboulon-Ktorza, N., Combescure, C., Elhai, M., Rozenberg, S., Gossec, L. \& Fautrel, B. (2013) Mortality in rheumatoid arthritis over the last fifty years: systematic review and meta-analysis. Joint Bone Spine, 80, 29-33.

Das De, S., Setiobudi, T., Shen, L. \& Das De, S. (2010) A rational approach to management of alendronate-related subtrochanteric fractures. J. Bone Joint Surg. Br., 92, 679-686.

Dell, R.M., Adams, A.L., Greene, D.F., Funahashi, T.T., Silverman, S.L., Eisemon, E.O., Zhou, H., Burchette, R.J. \& Ott, S.M. (2012) Incidence of atypical nontraumatic diaphyseal fractures of the femur. J. Bone Miner. Res., 27, 2544-2550.

Ettinger, B., Burr, D.B. \& Ritchie, R.O. (2013) Proposed pathogenesis for atypical femoral fractures: lessons from materials research. Bone, 55, 495-500.

Firestein, G.S., Budd, R.C., Gabriel, S.E., McInnes, I.B. \& O’Dell, J.R. (2017) Kelley \& Firestein's Textbook of Rheumatology, 10th ed., ELSEVIER, Philadelphia, PA.

Gedmintas, L., Solomon, D.H. \& Kim, S.C. (2013) Bisphosphonates and risk of subtrochanteric, femoral shaft, and atypical femur fracture: a systematic review and meta-analysis. $J$. Bone Miner. Res., 28, 1729-1737.

Gonzalez, A., Maradit Kremers, H., Crowson, C.S., Nicola, P.J., Davis, J.M., Therneau, T.M., Roger, V.L. \& Gabriel, S.E. (2007) The widening mortality gap between rheumatoid arthritis patients and the general population. Arthritis Rheum., 56, 3583-3587.

Hagen, J.E., Miller, A.N., Ott, S.M., Gardner, M., Morshed, S., Jeray, K., Alton, T.B., Ren, D., Abblitt, W.P. \& Krieg, J.C. (2014) Association of atypical femoral fractures with bisphosphonate use by patients with varus hip geometry. J. Bone Joint Surg. Am., 96, 1905-1909.

Hyodo, K., Nishino, T., Kamada, H., Nozawa, D., Mishima, H. \& Yamazaki, M. (2017) Location of fractures and the characteristics of patients with atypical femoral fractures: analyses of 38 Japanese cases. J. Bone Miner. Metab., 35, 209-214.

Kishimoto, H. \& Maehara, M. (2015) Compliance and persistence with daily, weekly, and monthly bisphosphonates for osteoporosis in Japan: analysis of data from the CISA. Arch. Osteoporos., 10, 231.

Koh, A., Guerado, E. \& Giannoudis, P.V. (2017) Atypical femoral fractures related to bisphosphonate treatment: issues and controversies related to their surgical management. Bone Joint J., 99-B, 295-302.

Koh, J.H., Myong, J.P., Jung, S.M., Lee, J., Kwok, S.K., Park, S.H. \& Ju, J.H. (2016) Atypical femoral fracture in rheumatoid arthritis patients treated with bisphosphonates: a nested casecontrol study. Arthritis Rheumatol., 68, 77-82.

Lo, J.C., Hui, R.L., Grimsrud, C.D., Chandra, M., Neugebauer, R.S., Gonzalez, J.R., Budayr, A., Lau, G. \& Ettinger, B. (2016) The association of race/ethnicity and risk of atypical femur fracture among older women receiving oral bisphosphonate therapy. Bone, 85, 142-147.

Meier, R.P., Ing Lorenzini, K., Uebelhart, B., Stern, R., Peter, R.E. \& Rizzoli, R. (2012) Atypical femoral fracture following bisphosphonate treatment in a woman with osteogenesis imperfecta: a case report. Acta Orthop., 83, 548-550.

Miyakoshi, N., Aizawa, T., Sasaki, S., Ando, S., Maekawa, S., Aonuma, H., Tsuchie, H., Sasaki, H., Kasukawa, Y. \& Shimada, Y. (2015) Healing of bisphosphonate-associated atypical femoral fractures in patients with osteoporosis: a comparison between treatment with and without teriparatide. J. Bone Miner. Metab., 33, 553-559.

Nakamura, T., Turner, C.H., Yoshikawa, T., Slemenda, C.W., Peacock, M., Burr, D.B., Mizuno, Y., Orimo, H., Ouchi, Y. \& Johnston, C.C. Jr. (1994) Do variations in hip geometry explain differences in hip fracture risk between Japanese and white Americans? J. Bone Miner. Res., 9, 1071-1076.

National Institute of Population and Social Security Research (2014) Japanese Mortality Database. http://www.ipss.go.jp/
[Accessed: August 05, 2017].

Nieves, J.W. \& Cosman, F. (2010) Atypical subtrochanteric and femoral shaft fractures and possible association with bisphosphonates. Curr. Osteoporos. Rep., 8, 34-39.

Odvina, C.V., Zerwekh, J.E., Rao, D.S., Maalouf, N., Gottschalk, F.A. \& Pak, C.Y. (2005) Severely suppressed bone turnover: a potential complication of alendronate therapy. J. Clin. Endocrinol. Metab., 90, 1294-1301.

Oh, Y., Wakabayashi, Y., Kurosa, Y., Fujita, K. \& Okawa, A. (2014) Potential pathogenic mechanism for stress fractures of the bowed femoral shaft in the elderly: mechanical analysis by the CT-based finite element method. Injury, 45, 1764-1771.

Ohta, D., Takakubo, Y., Okuda, S., Ito, J., Sasaki, K. \& Takagi, M. (2016) Atypical femoral fractures in our prefectural area. Nisseikaishi, 90, S826 (in Japanese).

Osteoporotic Committee of Japanese Orthopaedics Association (2015) Diagnostic manual of atypical femoral fracture. Nisseikaishi, 89, 959-973 (in Japanese).

Osteoporotic Committee of Japanese Orthopaedics Association (2016) The results of annual reports 2014 of atypical femoral fracture. Nisseikaishi, 90, 417-419 (in Japanese).

Sato, H., Kondo, N., Wada, Y., Nakatsue, T., Iguchi, S., Fujisawa, J., Kazama, J.J., Kuroda, T. Nakano, M., Endo, N. \& Narita, I. (2016) The Cumulative incidence of and risk factors for latent beaking in patients with autoimmune diseases taking longterm glucocorticoids and bisphosphonates. Osteoporos. Int., 27, 1217-1225.

Schilcher, J. (2015) High revision rate but good healing capacity of atypical femoral fractures. A comparison with common shaft fractures. Injury, 46, 2468-2473.

Schilcher, J., Koeppen, V., Aspenberg, P. \& Michaëlsson, K. (2014) Risk of atypical femoral fracture during and after bisphosphonate use. N. Engl. J. Med., 371, 974-976.

Schilcher, J., Michaëlsson, K. \& Aspenberg, P. (2011) Bisphosphonate use and atypical fractures of the femoral shaft. $N$. Engl. J. Med., 364, 1728-1737.

Shane, E., Burr, D., Abrahamsen, B., Adler, R.A., Brown, T.D., Cheung, A.M., Cosman, F., Curtis, J.R., Dell, R., Dempster, D.W., Ebeling, P.R., Einhorn, T.A., Genant, H.K., Geusens, P., Klaushofer, K., et al. (2014) Atypical subtrochanteric and diaphyseal femoral fractures: second report of a task force of the American Society for Bone and Mineral Research. J. Bone Miner. Res., 29, 1-23.

Shane, E., Burr, D., Ebeling, P.R., Abrahamsen, B., Adler, R.A., Brown, T.D., Cheung, A.M., Cosman, F., Curtis, J.R., Dell, R., Dempster, D., Einhorn, T.A., Genant, H.K., Geusens, P., Klaushofer, K., et al. (2010) Atypical subtrochanteric and diaphyseal femoral fractures: report of a task force of the American Society for Bone and Mineral Research. J. Bone Miner. Res., 25, 2267-2294.

Somford, M.P., Draijer, F.W., Thomassen, B.J., Chavassieux, P.M., Boivin, G. \& Papapoulos, S.E. (2009) Bilateral fractures of the femur diaphysis in a patient with rheumatoid arthritis on long-term treatment with alendronate: clues to the mechanism of increased bone fragility. J. Bone Miner. Res., 24, 17361740.

Taormina, D.P., Marcano, A.I., Karia, R., Egol, K.A. \& Tejwani, N.C. (2014) Symptomatic atypical femoral fractures are related to underlying hip geometry. Bone, 63, 1-6.

Watts, N.B., Aggers, D., McCarthy, E.F., Savage, T., Martinez, S., Patterson, R., Carrithers, E. \& Miller, P.D. (2017) Responses to treatment with teriparatide in patients with atypical femur fractures previously treated with bisphosphonates. J. Bone Miner. Res., 32, 1027-1033.

Yamagata prefecture, Health and longevity Promotion Section (2014) Rate of elderly people in Yamagata prefecture. http://www.pref.yamagata.jp/ou/kikakushinko/020052/tokei/jinkel.html. [Accessed: August 05, 2017]. 